\title{
How I set up positive end-expiratory pressure: evidence- and physiology-based!
}

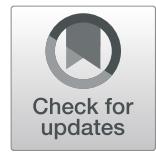

Emanuele Rezoagli ${ }^{1}$ and Giacomo Bellani ${ }^{1,2^{*}}$ (D)

Positive end-expiratory pressure (PEEP) is a cornerstone treatment for critically ill patients, with beneficial effects for acute respiratory distress syndrome (ARDS).

In ARDS, PEEP prevents alveolar collapse during expiration and counteracts increased surface tension due to surfactant impairment, alveolar over-deflation, and superimposed pressure. These mechanisms contribute to a reduction in intrapulmonary shunting. Furthermore, alveolar recruitment maintained through PEEP may translate into a higher end-expiratory lung volume (EELV), which often leads to better compliance of the respiratory system $\left(\mathrm{C}_{\mathrm{RS}}\right)$ and therefore a reduction in the driving pressure (DP), both of which are associated with higher survival rates [1]. Moreover, alveolar stability protects against intra-tidal recruitment/derecruitment (i.e., atelectrauma) [2] and imposed mechanical stresses and inflammation (i.e., biotrauma) [3], and it reduces ventilation heterogeneity [4].

Advantages of PEEP should be balanced against its potential disadvantages, namely, a reduction in cardiac output, an increase in pulmonary vascular resistance and alveolar dead space, and the risk of regional over-inflation [5].

\section{Recommended PEEP titration}

Current guidelines concerning moderate or severe ARDS recommend using higher rather than lower PEEP levels [6]. This recommendation is based on meta-analysis of individual patient data [7]. Furthermore, a subsequent ancillary analysis of LUNG SAFE reported that higher PEEP levels are associated with improved survival [8].

\section{How do we set up PEEP}

We present a PEEP titration strategy that relies heavily on physiological considerations, which is applied at our center. This opinion-based editorial is based on our interpretation of the evidence-based medical literature and

\footnotetext{
* Correspondence: giacomo.bellani1@unimib.it

${ }^{1}$ Department of Medicine and Surgery, University of Milan-Bicocca, Monza, Italy

${ }^{2}$ Department of Emergency and Intensive Care, San Gerardo Hospital, Monza taly
}



(c) The Author(s). 2019 Open Access This article is distributed under the terms of the Creative Commons Attribution 4.0 International License (http://creativecommons.org/licenses/by/4.0/), which permits unrestricted use, distribution, and

reproduction in any medium, provided you give appropriate credit to the original author(s) and the source, provide a link to the Creative Commons license, and indicate if changes were made. The Creative Commons Public Domain Dedication waiver (http://creativecommons.org/publicdomain/zero/1.0/) applies to the data made available in this article, unless otherwise stated.

\section{Driving pressure}

$\mathrm{C}_{\mathrm{RS}}$ is proportional to the "baby lung" size [9]; therefore, as a good proxy of EELV (albeit possibly influenced by other factors, such as chest-wall compliance), $C_{R S}$ tends to increase with recruitment but decreases again once overinflation begins. For this reason, changes in $\mathrm{C}_{\mathrm{RS}}$ are a key element for PEEP titration. At the same tidal volume $\left(V_{\mathrm{T}}\right)$, any change in $C_{R S}$ will be reflected in the driving pressure (DP) [10], or if pressure control is used, $V_{\mathrm{T}}$ increases for the same DP. We increase PEEP levels aiming to observe a decrease in DP at the same $V_{\mathrm{T}}$, likely indicating recruitment (not necessarily to a fully open lung). To facilitate this process, we could use a moderate recruitment maneuver (RM) (e.g., $40 \mathrm{cmH}_{2} \mathrm{O}$ for $20 \mathrm{~s}$ ) before increasing PEEP. An RM (rather than to correct hypoxemia) might work as a diagnostic tool (diagnostic RM) to explore the potential for lung recruitability, leading to an increase in PEEP levels in responders compared with non-responders. Simultaneously, if $\mathrm{C}_{\mathrm{RS}}$ decreases when PEEP is increased, indicating overdistension, we reduce either PEEP or $V_{\mathrm{T}}$ (if feasible in terms of $\mathrm{CO}_{2}$ elimination and respiratory rate). For a safe plateau pressure $\left(P_{\text {plat }}\right.$ ), one size (i.e., 30 $\mathrm{cmH}_{2} \mathrm{O}$ ) does not fit all, and if overdistension is an issue, our safety threshold for $P_{\text {plat }}$ is decreased.

\section{Oxygenation}

We always verify the response to gas exchange, primarily, an increase in $\mathrm{PaO}_{2}$ at a constant inspiratory $\mathrm{FiO}_{2}$, with constant or decreasing $\mathrm{PaCO}_{2}$. Although $\mathrm{PaO}_{2} /$ $\mathrm{FiO}_{2}$ is a poor proxy for alveolar recruitment, patients 


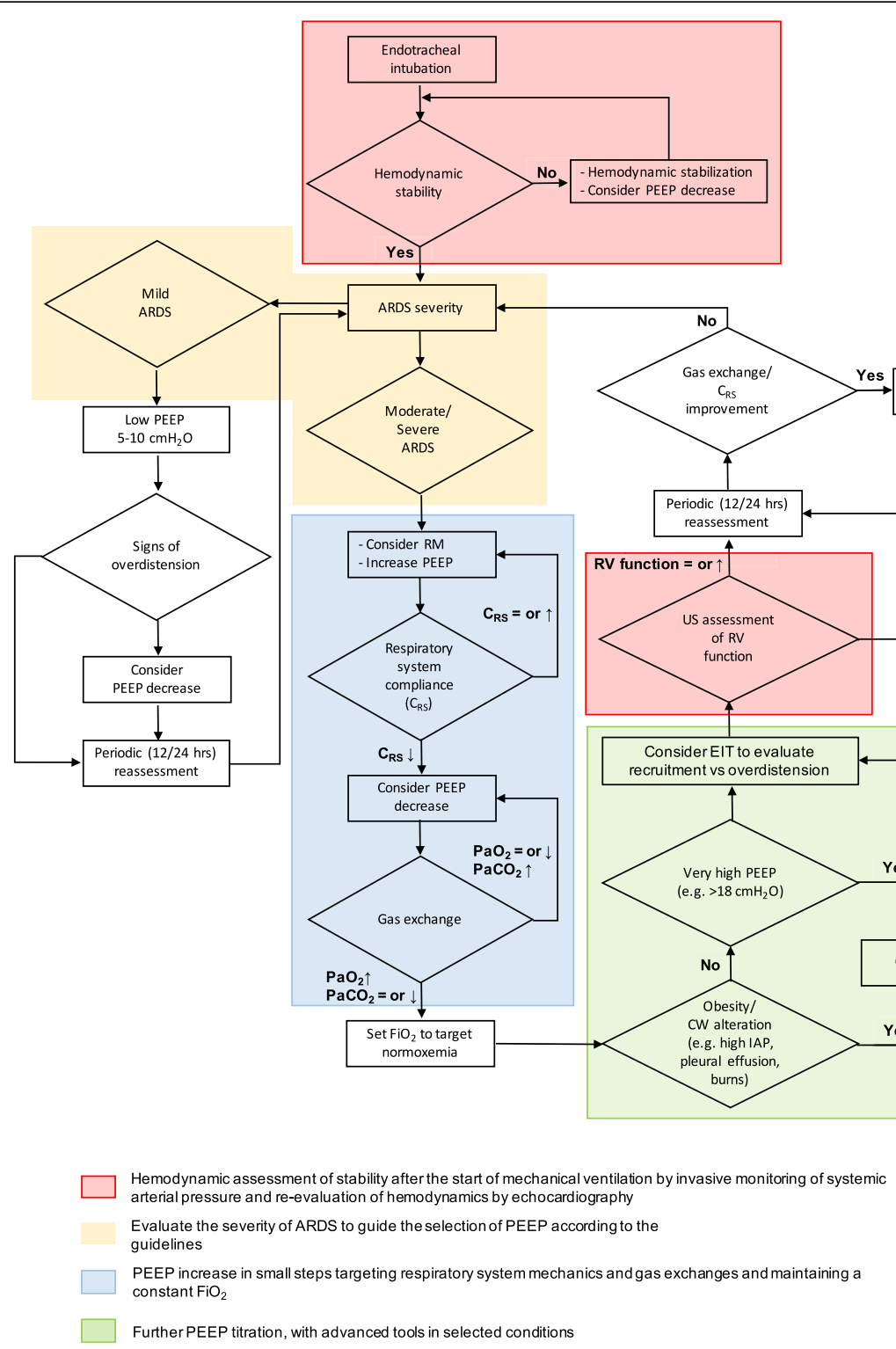

Fig. 1 Evidence-based decision-making flow chart for patients with ARDS requiring treatment using PEEP, according to patient physiological readouts. The approach we use to set up PEEP is applied either to patients in a supine position or to those with moderate-to-severe ARDS and prone positioning. Each step lasts normally 10 to $30 \mathrm{~min}$. The area in light blue indicates that $\mathrm{FiO}_{2}$ remains constant throughout the steps. After PEEP titration $\mathrm{FiO}_{2}$ can be decreased (or increased) to target normoxia. Pre-existing barotrauma and (according to some authors) elevated intracranial pressure should discourage from application of high PEEP. Abbreviations and symbols: ARDS, acute respiratory distress syndrome; $C_{R S}$ compliance of the respiratory system; CW, chest wall; EIT, electrical impedance tomography; $\mathrm{FiO}_{2}$, inspiratory oxygen fraction; PEEP, positive endexpiratory pressure; Pes, esophageal pressure; RM, recruitment maneuver; RV, right ventricle; US, ultrasound; $\uparrow$, increase; $\downarrow$, decrease; $=$, equal

who have responded to an increased PEEP with improved oxygenation have been reported to have a reduced risk of death [11]. As such, we prefer to uncouple the PEEP and $\mathrm{FiO}_{2}$ settings. Patients do not always show an improvement in oxygenation with higher PEEP levels. In this scenario, a strategy that mandates simultaneous increase of these parameters (e.g., $\mathrm{PEEP} / \mathrm{FiO}{ }_{2}$ tables) would recommend a further PEEP increase combined with $\mathrm{FiO}_{2}$. Finally, an increase in $\mathrm{PaCO}_{2}$ levels in relation to a PEEP increase should be an immediate alert for a risk of overdistension.

Of late, and more frequently, we are taking advantage of bedside electrical impedance tomography (EIT) to corroborate our PEEP titration procedure. We propose a 2-step strategy. First, we perform a diagnostic RM to evaluate the potential for lung recruitment. Second, we increase the PEEP level in small increments (e.g., 2 $\mathrm{cmH}_{2} \mathrm{O}$ ) until it is sufficient to maintain EELV stability, 
according to the end-expiratory lung impedance signal. This approach leads to an improvement in arterial oxygenation and a reduction in the DP and provides regional information concerning the balance between alveolar overdistension and collapse [12].

We typically confine the measurement of esophageal pressure to selected clinical conditions (Fig. 1).

\section{Controversies concerning the use of higher PEEP levels}

The described approach might appear to be contradictory to the recent literature [13] reporting that patients receiving an RM followed by a decremental PEEP trial, according to $C_{R S}$, have increased mortality rates. However, we consider that this study does not invalidate the concept of higher PEEP levels being associated with a lower DP, as it combined other procedures that might have contributed to the higher mortality, such as an aggressive RM of up to $60 \mathrm{cmH}_{2} \mathrm{O}$ (reduced to $50 \mathrm{cmH}_{2} \mathrm{O}$ after $50 \%$ enrollment) and lasting several minutes overall, which required important fluid expansion, neuromuscular blocking agents, and an additional RM performed after PEEP titration. Furthermore, the decision to set PEEP at $2 \mathrm{cmH}_{2} \mathrm{O}$ above the best $\mathrm{C}_{\mathrm{RS}}$ likely led to regional overdistension of the nondependent lung.

\section{Future perspectives and conclusion}

It is known that a high PEEP level does not fit all; therefore, innovative concepts such as the different responses of hypo- and hyper-inflammatory ARDS phenotypes to PEEP [14] and the use of population enrichment for inclusion in trials [15] are encouraging.

In the meantime, we set PEEP levels for patients with moderate or severe ARDS that aim for a moderate reasonable recruitment, given the challenges of full lung recruitment, according to incremental PEEP steps (possibly interspersed with short diagnostic RMs) and seek improvements in functional and physiologic readouts, such as $C_{R S}$, gas exchange, and EIT.

\begin{abstract}
Abbreviations
ARDS: Acute respiratory distress syndrome; $C_{R S}$ : Compliance of the respiratory system; DP: Driving pressure; EELV: End-expiratory lung volume; EIT: Electrical impedance tomography; $\mathrm{FiO}_{2}$ : Inspiratory fraction of oxygen; $\mathrm{PaCO}_{2}$ : Arterial pressure of carbon dioxide; $\mathrm{PaO}_{2}$ : Arterial pressure of oxygen; PEEP: Positive end-expiratory pressure; $P_{\text {plat }}$ : Plateau pressure; RM: Recruitment maneuver; $V_{T}$ : Tidal volume
\end{abstract}

\section{Acknowledgements}

We are grateful to Prof. Antonio Pesenti and Prof. Giacomo Grasselli for their invaluable suggestions in reviewing this manuscript.

\section{Authors' contributions}

$E R$ and $G B$ conceived the study, reviewed the literature, wrote the manuscript, critically revised it, and read and approved the final manuscript.

Funding

The study was supported by Institutional funds.
Availability of data and materials

Not applicable

Ethics approval and consent to participate

Not applicable

Consent for publication

Not applicable

Competing interests

G.B. received lecturing fees from Draeger. E.R. declares that he has no competing interests.

Received: 13 September 2019 Accepted: 6 December 2019

Published online: 16 December 2019

\section{References}

1. Sahetya SK, Goligher EC, Brower RG. Fifty years of research in ARDS. Setting positive end-expiratory pressure in acute respiratory distress syndrome. Am J Respir Crit Care Med. 2017;195(11):1429-38.

2. Caironi $P$, Cressoni M, Chiumello D, Ranieri M, Quintel M, Russo SG, Cornejo R, Bugedo G, Carlesso E, Russo R, Caspani L, Gattinoni L. Lung opening and closing during ventilation of acute respiratory distress syndrome. Am J Respir Crit Care Med. 2010;181(6):578-86.

3. Tremblay LN, Slutsky AS. Ventilator-induced injury: from barotrauma to biotrauma. Proc Assoc Am Physicians. 1998:110:482-8.

4. Cressoni M, Cadringher P, Chiurazzi C, et al. Lung inhomogeneity in patients with acute respiratory distress syndrome. Am J Respir Crit Care Med. 2014; 189(2):149-58

5. Luecke T, Pelosi P. Clinical review: positive end-expiratory pressure and cardiac output. Crit Care. 2005;9(6):607-21.

6. Fan E, Del Sorbo L, Goligher EC, et al. American Thoracic Society, European Society of Intensive Care Medicine, and Society of Critical Care Medicine. An Official American Thoracic Society/European Society of Intensive Care Medicine/Society of Critical Care Medicine clinical practice guideline: mechanical ventilation in adult patients with acute respiratory distress syndrome. Am J Respir Crit Care Med. 2017:195(9):1253-63.

7. Briel M, Meade M, Mercat A, et al. Higher vs lower positive end-expiratory pressure in patients with acute lung injury and acute respiratory distress syndrome: systematic review and meta-analysis. JAMA. 2010;303(9):865-73.

8. Laffey JG, Bellani G, Pham T, et al. LUNG SAFE Investigators and the ESICM Trials Group. Potentially modifiable factors contributing to outcome from acute respiratory distress syndrome: the LUNG SAFE study. Intensive Care Med. 2016:42(12):1865-76.

9. Gattinoni L, Pesenti A. The concept of "baby lung". Intens Care Med. 2005; 31(6):776-84

10. Amato MB, Meade MO, Slutsky AS, et al. Driving pressure and survival in the acute respiratory distress syndrome. N Engl J Med. 2015;372(8):747-55.

11. Goligher EC, Kavanagh BP, Rubenfeld GD, et al. Oxygenation response to positive end-expiratory pressure predicts mortality in acute respiratory distress syndrome. A secondary analysis of the LOVS and ExPress trials. Am J Respir Crit Care Med. 2014;190(1):70-6.

12. Eronia N, Mauri T, Maffezzini E, et al. Bedside selection of positive endexpiratory pressure by electrical impedance tomography in hypoxemic patients: a feasibility study. Ann Intensive Care. 2017;7(1):76.

13. Writing Group for the Alveolar Recruitment for Acute Respiratory Distress Syndrome Trial (ART) Investigators, Cavalcanti AB, Suzumura ÉA, Laranjeira $L N$, et al. Effect of lung recruitment and titrated positive end-expiratory pressure (PEEP) vs low PEEP on mortality in patients with acute respiratory distress syndrome: a randomized clinical trial. JAMA. 2017;318(14):1335-45.

14. Calfee CS, Delucchi K, Parsons PE, et al. NHLBI ARDS Network. Subphenotypes in acute respiratory distress syndrome: latent class analysis of data from two randomised controlled trials. Lancet Respir Med. 2014;2(8):611-20.

15. Shankar-Hari M, Rubenfeld GD. Population enrichment for critical care trials: phenotypes and differential outcomes. Curr Opin Crit Care. 2019;25(5):489-97.

\section{Publisher's Note}

Springer Nature remains neutral with regard to jurisdictional claims in published maps and institutional affiliations. 